\title{
Neuromotor Development of Children Aged 6 and 7 Years Born before the 30th Week Gestation
}

\author{
Joanna Majewska $\mathbb{D}^{1,2}$ Katarzyna Zajkiewicz $\mathbb{D}^{1,2}$ Kamila Wacław-Abdul, ${ }^{1}$ \\ Joanna Baran $\mathbb{D}^{1,2}$ and Daniel Szymczyk $\mathbb{D}^{1,2}$ \\ ${ }^{1}$ Institute of Physiotherapy, Medical Faculty, University of Rzeszow, Rejtana 16c, 35-959 Rzeszów, Poland \\ ${ }^{2}$ Centre for Innovative Research in Medical and Natural Sciences, Medical Faculty, University of Rzeszow, Warzywna 1a, \\ 35-310 Rzeszów, Poland \\ Correspondence should be addressed to Joanna Majewska; joadud@gmail.com
}

Received 14 December 2017; Revised 19 February 2018; Accepted 13 March 2018; Published 20 May 2018

Academic Editor: Imelda de Groot

Copyright (C) 2018 Joanna Majewska et al. This is an open access article distributed under the Creative Commons Attribution License, which permits unrestricted use, distribution, and reproduction in any medium, provided the original work is properly cited.

\begin{abstract}
Introduction. The aim of this study was to evaluate and compare the level of neuromotor function and somatic development in 6- and 7-year-old children born before the 30th week gestation with that in full-term children at the same age, as well as the correlation between prematurity and motor development. Material and Methods. The study group consisted of prematurely born 40 children. Their mean gestational age at birth was $27.8 \pm 1.6$ weeks (range $24-30$ weeks). The control group consisted of 40 healthy children born with normal birth weight $(>2500 \mathrm{~g}$ ). The neuromotor function was assessed using Touwen neurological examination criteria. During the examination, the attention was focused on the hand preference, laterality, synkinesis, and asymmetry. In addition, children's weight, height, and BMI index were measured. Results. Premature children showed much worse results than full-term ones in hand function $(p<0,001)$. They obtained the best results in paper tearing while crossing the body midline turned out to be the most difficult. Considering the quality of walking, the biggest difficulty for the premature children was to walk backwards along the straight line while during normal walking they showed the best results. The results for the muscle tone subcategory in the study group were also significantly worse than those in control group $(p<0,001)$, as well as the total outcome for the movement coordination and diadochokinesis subcategories $(p<0,001)$. Conclusion. The nondisabled, prematurely born children have significantly lower average outcomes regarding hand function, quality of walking, muscle tone, coordination, and diadochokinesis at age of six to seven, compared to the full-term peers.
\end{abstract}

\section{Introduction}

The incidence of preterm delivery has been increasing and the survival rate of preterm children has risen steadily due to advances in obstetric and neonatal intensive care [1]. According to the World Health Organization (WHO), the infants born before 32nd week of pregnancy are considered very preterm (VPT) infants [2]. The WHO estimated that, in 2015, 15 million infants were born before 37 weeks of gestation. Across 184 countries, the rate of preterm birth ranges from $5 \%$ to $18 \%$. Preterm infants are being allocated to two categories according to their birth weight: low birth weight (LBW) and very low birth weight (VLBW) when their birth weight ranges from $<2500$ grams and $<1500$ grams, respectively [3].
Recent studies show a diminishing prevalence of severe motor disabilities in preterm children, but mild neurodevelopmental impairments remain dominating problems for preschool and school-aged children [4]. Children born prematurely may present delays in the motor [5-8], adaptive [9], cognitive $[5,6,8,10]$, and language $[5,6,8,11]$ domains, even if the deficits in these areas are subtle [5]. These domains are interdependent; that is, each one influences and is influenced by the other.

Motor deficits in coordination, balance, gross and fine motor control, visual spatial, and visual motor integration have been reported in preterm children without $\mathrm{CP}$, but can be more accurately evaluated at a later age $[12,13]$. Among other characteristics, parents describe such children 
as "clumsy," with decreased hand-eye coordination and motor control challenges. These mild neurodevelopmental impairments tend to persist into later childhood, which might challenge children's successful participation in everyday life both at school and at home $[14,15]$.

Although long-term developmental changes in preterm children are well described in the literature, the occurrence of these difficulties at preschool age is less documented. Neither the degree of prematurity nor early cognitive testing predicts which children within nondisabled, preterm groups will have poorer functional performance and will require extra services [16]. Therefore, further investigation to obtain a more indepth understanding of the impairments and activity limitations among nondisabled extremely preterm or ELBW children at preschool age is required. The findings will provide useful information to assist in the development of strategies to provide better results for this population of children.

\section{Purpose}

The aim of this study was to evaluate and compare the level of neuromotor function and somatic development in 6- and 7year-old children born before the 30th week gestation with that in full-term children at the same age, as well as the correlations between prematurity and motor development.

\section{Material and Methods}

Ethical approval for the study was granted by the Ethics Committee of the University of Rzeszow. Written formal consent was obtained from the parents of all subjects who participated in this study.

3.1. Participants. Data for this study was collected between August 2007 and July 2009. The study group consisted of prematurely born 40 children (19 females, 21 males), whose personal data were acquired from the database of the Neonatology Department at the County Hospital No. 2 in Rzeszów, Poland. Their mean gestational age at birth was $27.8 \pm 1.6$ weeks (range 24-30 weeks). Mean birth weight was $1124 \mathrm{~g}$ (range $570 \mathrm{~g}-1300 \mathrm{~g}$ ). Mean chronological age was 6 years and 8 months (range from 5 years and 9 months to 7 years and 4 months). The authors excluded children with major congenital malformations, genetic chromosomal abnormalities, metabolic disorders, cerebral palsy (CP) that interfered with locomotion, congenital infections, sign of encephalopathy or seizures during their neonatal course, and retinopathy of prematurity greater than stage 2 , because it had been assumed that these infants would have already developed poor neurodevelopmental disorders when compared with healthy children. Children with a visual impairment not corrected by wearing corrective lenses and those with a hearing impairment not corrected by hearing aids were also excluded. The early medical status of preterm infants was extracted from medical records. Then parents of eligible children were contacted to inquire whether they wished to receive further information and appropriate consent forms to complete.

The control group consisted of 40 healthy children (20 females, 20 males) born with normal birth weight (>2500 g), the pupils of primary schools in Rzeszów who were born between February 2002 and January 2003. First, requests to the headmasters of these schools were submitted in order to obtain the school's permission for participation in the research. Next, the children received a letter to their parents, which explained the purpose of the study and requested their consent regarding the children participation in this study. Children with a history of admission to neonatal intensive care unit, gestation of $<37$ or $>42$ weeks, infants born from multiple pregnancies, and those with musculoskeletal, neurological, genetic, and other disorders that could negatively influence motor development were excluded from the control group. The proper developmental status of children in the control group had been confirmed by paediatricians based on previous medical periodic examinations. Data concerning children's birth and neonatal status were provided by their parents. Children whose parents signed the formal written consent confirming their participation in the study were evaluated.

3.2. Procedure. Standardized and age-specific assessment, according to Touwen neurological examination criteria for children with minor neurological dysfunction (MND), was used in this study [17]. The Touwen neurological examination is free of charge, well-known, and commonly used assessment method, which is specially designed for the evaluation of the following minor neurological dysfunction in children: mild abnormalities in muscle tone (clinical test by passive movement), diadochokinesis, quality of walking, posture, mild problems with coordination, and hand function.

Modified, performance based assessment criteria were applied for the evaluation of all the tests in our study, considering all subcategories (hand function, quality of walking, muscle tone, movement coordination, and diadochokinesis). Each test was scored using 4-point scale, from 0 to $3(0=$ lowest possible score up to 3 = best, optimal score). Then the numeric scores were categorized as a "lack of skills," weak, medium and "optimal," respectively. Additionally, total outcome in each subcategory was calculated, as a percentage of optimal score, in the following manner: each child score described as "lack of skills" was graded as $0 \%$ while that described as "optimal" was graded as $100 \%$. Overall outcome, as a sum of the average scores in each subcategories, divided by the number of subcategories, was also calculated. During the examination, the attention was also focused on the hand preference, laterality, synkinesis, and asymmetry. In addition, children's weight (kilograms), height (centimeters), and the $\mathrm{BMI}$ index $(\mathrm{kg} \backslash \mathrm{m} 2)$ were measured.

All assessments were completed by the same experienced physiotherapist who was trained in testing protocol and who had no previous access to information regarding the birth status and medical history of the subjects. Each child was evaluated under the same environmental conditions and completed all the testing in one day. Each assessment took approximately one hour and took place in the County Hospital No. 2 in Rzeszów.

3.3. Statistical Analysis. All calculations and statistical analyses were performed using STATISTICA ver. 10.0 (StatSoft, 
TABLE 1: Somatic development of children.

\begin{tabular}{|c|c|c|c|c|c|c|c|c|c|c|c|}
\hline & \multicolumn{5}{|c|}{ Study group } & \multicolumn{5}{|c|}{ Control group } & \multirow{2}{*}{$p$} \\
\hline & $\bar{x}$ & $\mathrm{Me}$ & Min & Max & s & $\bar{x}$ & $\mathrm{Me}$ & Min & Max & $\mathrm{s}$ & \\
\hline Body height & 120,9 & 121,0 & 104 & 133 & 6,2 & 120,4 & 120,0 & 112 & 134 & 5,1 & 0,668 \\
\hline Body mass & 22,8 & 24,0 & 14 & 30 & 4,0 & 22,9 & 22,0 & 18 & 32 & 3,7 & 0,843 \\
\hline BMI & 15,5 & 16,0 & 11,8 & 19,0 & 2,0 & 15,7 & 15,6 & 12,3 & 22,2 & 1,9 & 0,527 \\
\hline
\end{tabular}

Max: maximum value; Me: median; Min: minimal value; $p$ : test probability value; s: standard deviation; $\bar{x}$ : mean.

TABLE 2: Hand preferences in study and control group.

\begin{tabular}{lccc}
\hline $\begin{array}{l}\text { Hand preference } \\
(p=0,003)\end{array}$ & Study & Control & Total \\
\hline Right handed & $27(68 \%)$ & $35(88 \%)$ & 62 \\
Left handed & $3(8 \%)$ & $5(13 \%)$ & 8 \\
Both handed & $10(25 \%)$ & $0(0 \%)$ & 10 \\
Total & 40 & 40 & 80 \\
\hline
\end{tabular}

$p$ : test probability value.

Poland). Statistical significance level was assumed at $p \leq$ 0.05. The Shapiro-Wilk test was used for the evaluation of normal data distribution. Basic descriptive statistical analyses were conducted for all variables. Adequate parametric or nonparametric statistical tests, depending on the data type and distribution, were used for the comparison of the results between the groups. Independent $t$-test was used for normally distributed data. The Chi-Square test was used to determine statistically significant differences for categorical measures while Spearman's rank correlation coefficient was used to measure the strength and direction of correlation between two sets of data.

\section{Results}

There were no statistically significant differences between the level of somatic development of children in both groups (Table 1).

There are statistically significant differences regarding hand preferences between the groups; in the study group there were less right handed children and more both handed. Sixty-eight percent of the children in study group were right handed compared to $88 \%$ in the control group. Moreover, the fact that $25 \%$ of the subjects in the group of preterm children were both handed while in control group none of children presented both hand preferences seems to be very interesting (Table 2).

The differences of the results of all tests in hand function subcategory between the study and control group were statistically significant. Premature children showed worse results than those born full term. Considering hand function, premature children obtained the best results in paper tearing while crossing the body midline turned out to be the most difficult (Table 3).

In the quality of walking subcategory, the biggest difficulty for premature children was to walk backwards along straight line while assessment of normal walking provided the best results (Table 4).

The results of all tests in muscle tone subcategory were significantly worse in the study group, compared to the control group (Table 5).

In all tests evaluating movement coordination, the children from study group obtained significantly worse results than the children from control group (Table 6).

In diadochokinesis subcategory the biggest difficulty for premature children were observed in reaching for the ears with crossed arms test and finger-opposition test (Table 7).

Comparison of the total outcomes for each of the functional subcategories in our study revealed significant differences between preterm children and their full-term peers $(p<0,001)$. The difference in overall outcome (average level of the results considering all subcategories) was also statistically significant $(p<0,001)$ (Table 8 ).

The correlations between gestation time and the results of each test used in our study, as well as total outcome for the subcategory, were also analysed. The degree of prematurity had statistically significant influence only on the results of three tests in the hand function subcategory, while the strength of those correlations was moderate (Table 9).

\section{Discussion}

Both technological advances in neonatology over the last few decades and increased survival of preterm infants have made it important to consider the long-term outcomes concerning their developmental status. Children born prematurely may present developmental delays even in the absence of severe neurological disorders $[6-8,18-20]$. Many researchers are interested in investigating the preterm children population without major neurological impairments because milder functional problems are often not being diagnosed until these children reach their school age [21]. These subtle movement dysfunctions do not occur due to known physical disorders, such as cerebral palsy, hemiplegia, or muscular dystrophy. It is estimated that $40-70 \%$ of children born prematurely are showing minor disabilities such as mild motor problems and poor adaptive behaviors during preschool and school years [9]. School children born with extreme prematurity, without any significant neurological problem or developmental impairment presented worse performance in sensorimotor and visuospatial competencies, as well as in attention and executive function when compared with children born at term [10]. Therefore, it is very important to identify potential neurodevelopmental impairments at younger age in order to 


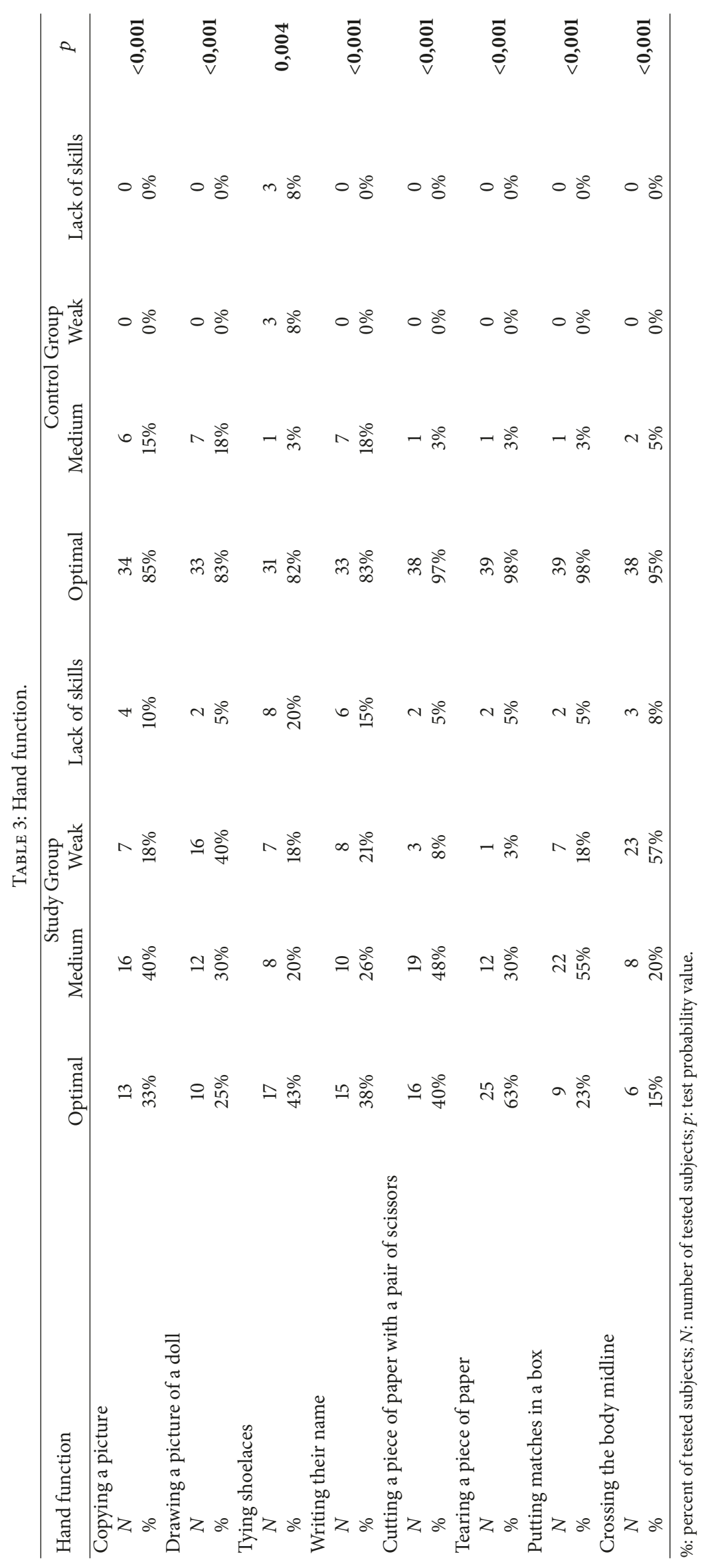


BioMed Research International

5

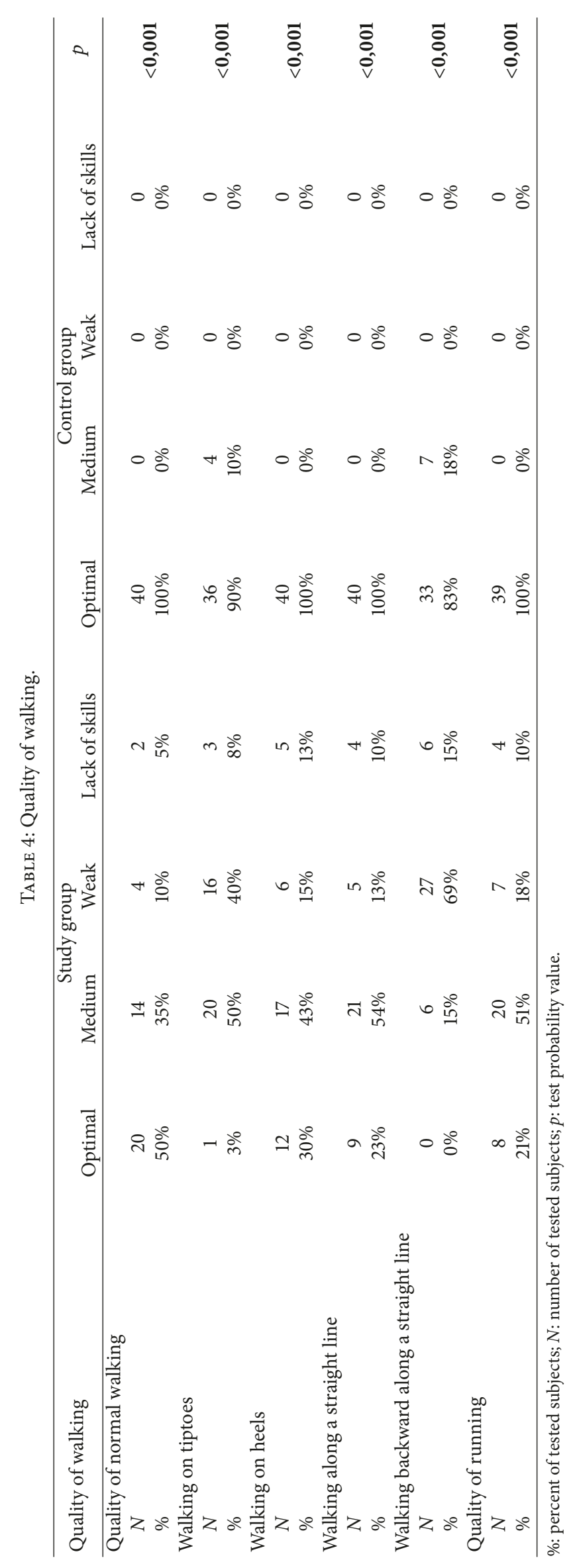




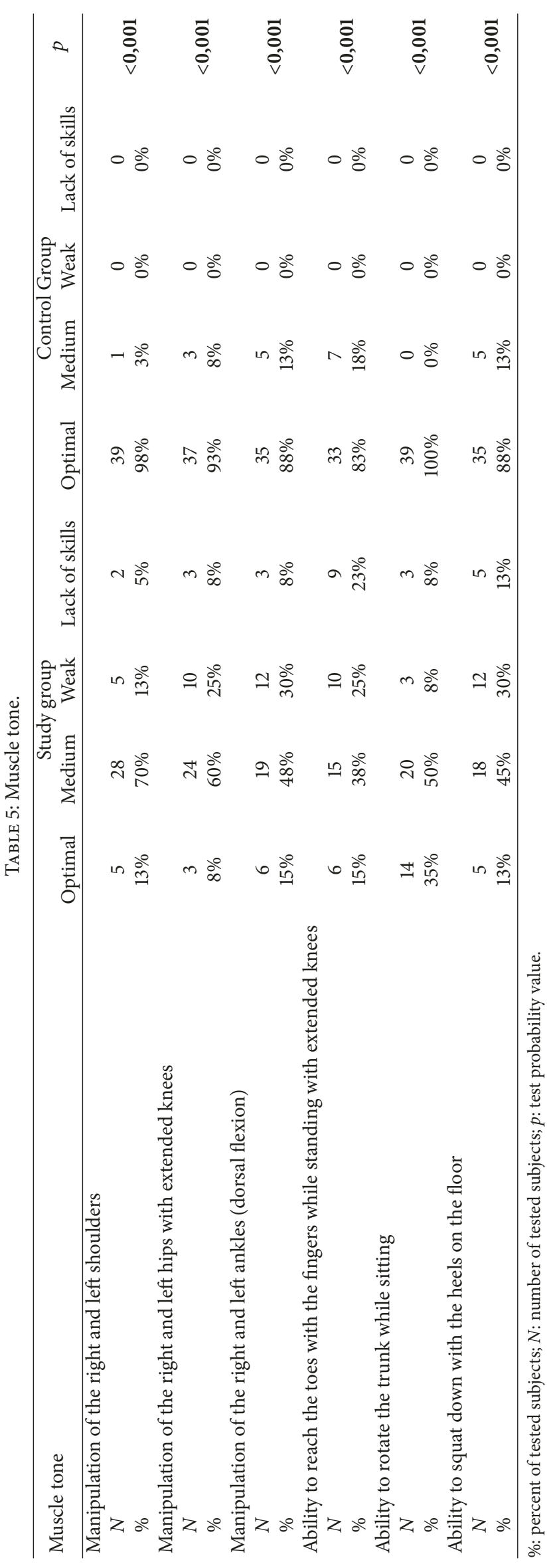




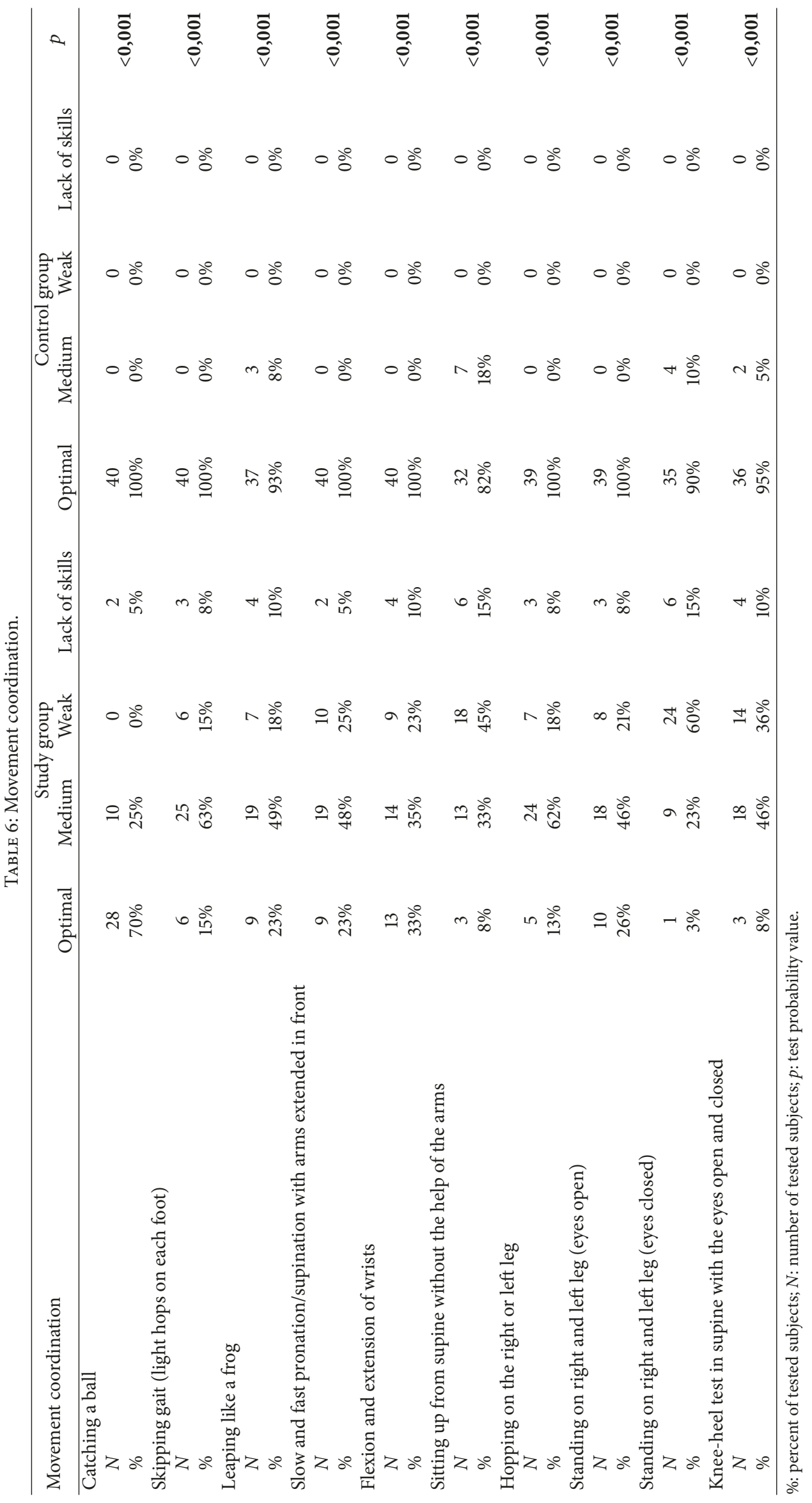




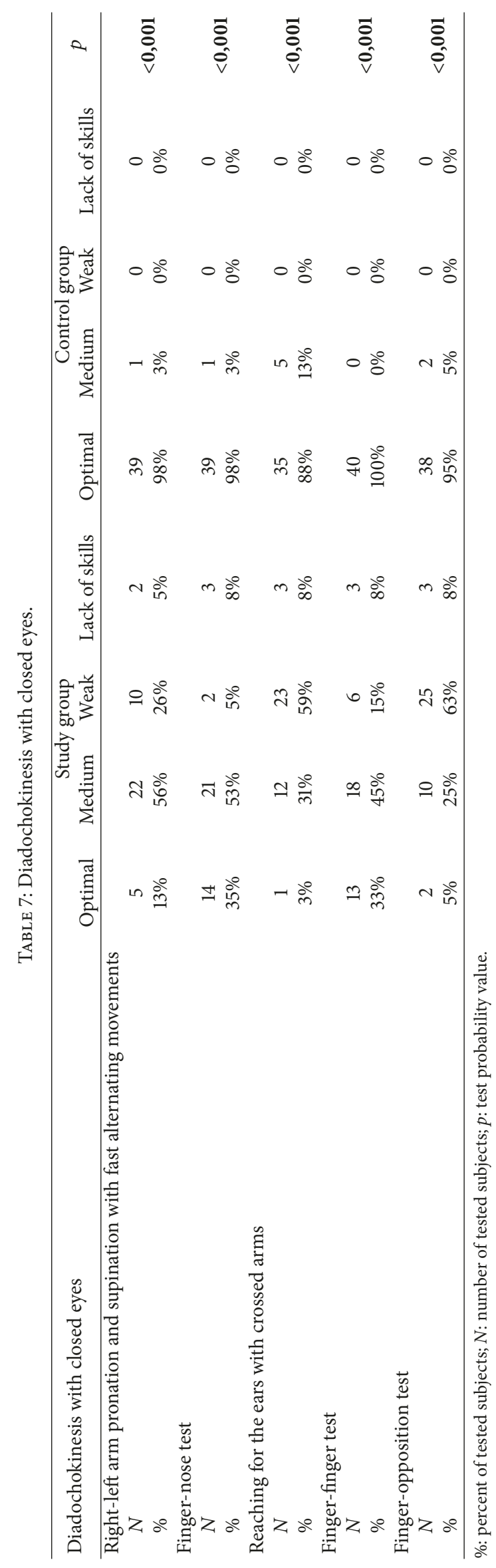




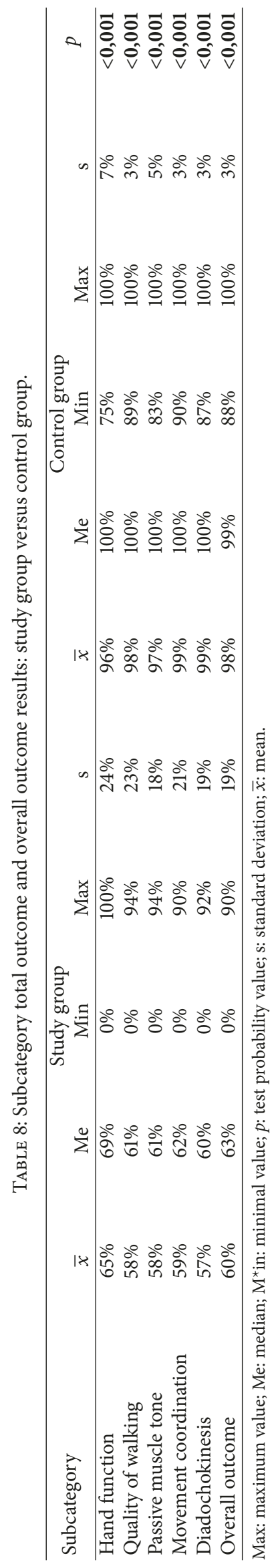


TABLE 9: Evaluation of correlation with gestation time.

Hand function

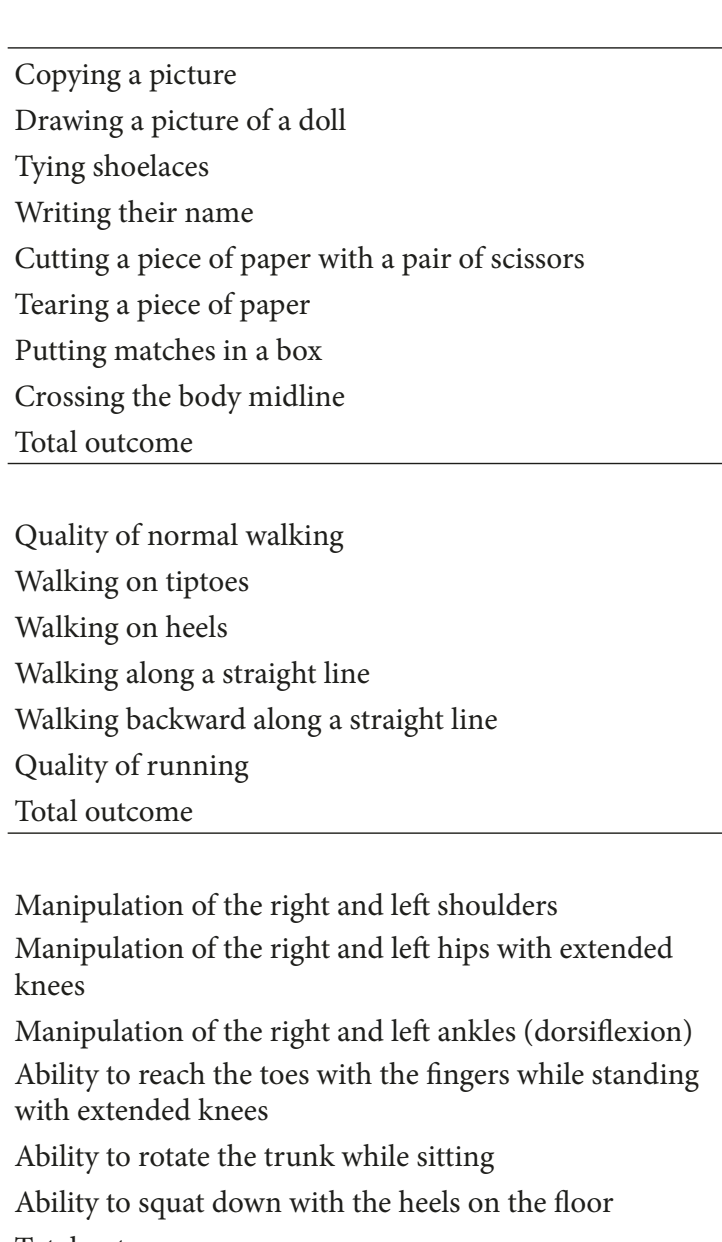

Total outcome
Correlation with gestation time

$R$

0,46

0,38

0,24

0,37

$-0,02$

0,16

0,09

0,20

0,33

Quality of walking

$-0,01$

0,953

0,07

0,665

0,04

0,820

$-0,04$

0,813

0,03

0,870

0,01

0,959

$-0,01$

0,953

Muscle tone

0,25

0,116

0,22

0,166

0,14

0,375

$-0,01$

0,963

0,00

0,987

0,03

0,856

0,18

0,267

Movement coordination

Catching a ball

0,04

0,799

Skipping gait (light hops on each foot)

0,14

0,402

Leaping like a frog

0,11

0,496

Slow and fast pronation/supination with arms extended in front

0,01

0,973

$-0,07$

0,648

$-0,01$

0,944

Sitting up from supine without the help of the arms

Hopping on the right or left leg

0,23

0,155

0,26

0,110

0,04

0,783

$-0,05$

0,745

0,04

0,790

Diadochokinesis with closed eyes

Right-left arm pronation and supination with fast alternating movements

0,08

Finger-nose test

Reaching for the ears with crossed arms

Finger-finger test

Finger-opposition test

0,28

$R$ : correlation; $p$ : test probability value. 
introduce more efficient consultation and timely intervention.

The objective of this study was to determine whether children born before 30 weeks of pregnancy, who seemed to be free of serious neurological disorders, would develop similar growth patterns and neurodevelopmental performance at preschool age, compared with their full-term peers.

One of the diagnostic methods, suitable for children with motor development disorders, which was used in this study, was Touwen neurological examination. This is a standardized and age-specific assessment tool that focuses on the presence of minor neurological dysfunction.

The results of the recent study demonstrate that a significant amount of apparently normal preterm children had worse motor and functional performance at preschool age than their full-term peers [17].

In the scientific studies concerning motor development of preterm children, the incidence of motor impairment is reported to vary from 9.5 to $51 \%$ [22-28]. These children may also exhibit other learning difficulties. Several studies have attempted to assess if motor impairments are being associated with learning impairments in preterm children. Motor impairments are definitely associated with intellectual estimations of both the visual and verbal domains [22]. When children with motor impairments are compared with their full-term peers, differences are seen in a wide variety of performed intellectual and academic tasks $[23,24]$.

Analysis of the relationship between the duration of pregnancy and the results of the individual tests showed that the degree of prematurity affects, in a statistically significant way, only the results of the three tests in the hand function subcategory. However, the strength of these correlations was moderate. It has been reported by de Kieviet et al. that gestational age is related to delayed motor performance occurring during early developmental period in children under 5 years of age [29].

Defining mild neuromotor impairments at preschool age, as a valid marker of long-term impairments, allows proactive support and prospective allocation of resources to be directed to those who are most likely to struggle with future problems and limitations in personal, social, and academic life.

\section{Conclusion}

The results of our study indicate that the nondisabled, preterm children have lower average outcomes concerning hand function, quality of walking, muscle tone, coordination, and diadochokinesis at the age of six to seven, compared to their full-term peers. It seems that, with time, these particular children may be prone to emerging problems in the future. Therefore, ongoing screening of these children seems to be essential. Involvement of nondisabled, preterm children in appropriate intervention programs may facilitate their optimal development, maintain adequate motor performance, and minimize the development of long-term impairments.

\section{Conflicts of Interest}

The authors declare that there are no conflicts of interest regarding the publication of this paper.

\section{References}

[1] R. L. Goldenberg, J. F. Culhane, J. D. Iams, and R. Romero, "Epidemiology and causes of preterm birth," The Lancet, vol. 371, no. 9606, pp. 75-84, 2008.

[2] World Health Organization, International Statistical Classification of Diseases And Related Health Problems, WHO, Geneva, Switzerland, 2004.

[3] World Health Organization, "Fact Sheet No. 363, Preterm Birth," 2015, http://www.who.int/mediacentre/factsheets/fs363/ en/.

[4] B. Larroque, P.-Y. Ancel, S. Marret et al., "Neurodevelopmental disabilities and special care of 5-year-old children born before 33 weeks of gestation (the EPIPAGE study): a longitudinal cohort study," The Lancet, vol. 371, no. 9615, pp. 813-820, 2008.

[5] G. S. Ross, L. M. Foran, B. Barbot, K. M. Sossin, and J. M. Perlman, "Using cluster analysis to provide new insights into development of very low birthweight (VLBW) premature infants," Early Human Development, vol. 92, pp. 45-49, 2016.

[6] D. E. Ballot, J. Potterton, T. Chirwa, N. Hilburn, and P. A. Cooper, "Developmental outcome of very low birth weight infants in a developing country," BMC Pediatrics, vol. 12, article no. 11, 2012.

[7] H. K. Brown, K. N. Speechley, J. Macnab, R. Natale, and M. K. Campbell, "Mild prematurity, proximal social processes, and development," Pediatrics, vol. 134, no. 3, pp. e814-e824, 2014.

[8] C. C. Guerra, M. C. de Moraes Barros, A. L. Goulart, L. V. Fernandes, B. I. Kopelman, and A. M. dos Santos, "Premature infants with birth weights of 1500-1999 g exhibit considerable delays in several developmental areas," Acta Paediatrica, vol. 103, no. 1, pp. el-e6, 2014.

[9] T.-H. Howe, C.-F. Sheu, Y.-W. Hsu, T.-N. Wang, and L.-W. Wang, "Predicting neurodevelopmental outcomes at preschool age for children with very low birth weight," Research in Developmental Disabilities, vol. 48, pp. 231-241, 2016.

[10] H. Kallankari, T. Kaukola, P. Olsén, M. Ojaniemi, and M. Hallman, "Very preterm birth and foetal growth restriction are associated with specific cognitive deficits in children attending mainstream school," Acta paediatrica (Oslo, Norway: 1992), vol. 104, no. 1, pp. 84-90, 2015.

[11] N. Barre, A. Morgan, L. W. Doyle, and P. J. Anderson, "Language abilities in children who were very preterm and/or very low birth weight: A meta-analysis," Journal of Pediatrics, vol. 158, no. 5, pp. 766-el, 2011.

[12] J. Williams, K. J. Lee, and P. J. Anderson, "Prevalence of motorskill impairment in preterm children who do not develop cerebral palsy: A systematic review," Developmental Medicine \& Child Neurology, vol. 52, no. 3, pp. 232-237, 2010.

[13] J. Edwards, M. Berube, K. Erlandson et al., "Developmental coordination disorder in school-aged children born very preterm and/or at very low birth weight: A systematic review," Journal of Developmental \& Behavioral Pediatrics, vol. 32, no. 9, pp. 678-687, 2011.

[14] J. Fawke, "Neurological outcomes following preterm birth," Seminars in Fetal and Neonatal Medicine, vol. 12, no. 5, pp. 374382, 2007.

[15] J. P. Piek, L. Dawson, L. M. Smith, and N. Gasson, "The role of early fine and gross motor development on later motor and cognitive ability," Human Movement Science, vol. 27, no. 5, pp. 668-681, 2008.

[16] M. Danks, M. F. Maideen, Y. R. Burns et al., "The long-term predictive validity of early motor development in "apparently 
normal" ELBW survivors," Early Human Development, vol. 88, no. 8, pp. 637-641, 2012.

[17] B. C. L. Touwen, Examination of the Child with Minor Neurological Dysfunction, TheLavenham Press LTD, Lavenham, England, 2nd edition, 1979.

[18] B. Resch, E. Resch, U. Maurer, and W. Mueller, "Periventricular leukomalacia and neurodevelopmental outcome," Journal of Pediatrics, vol. 159, no. 6, p. 1049, 2011.

[19] H. A. Samra, J. M. Mcgrath, and M. Wehbe, "An Integrated Review of Developmental Outcomes and Late-Preterm Birth," JOGNN - Journal of Obstetric, Gynecologic, and Neonatal Nursing, vol. 40, no. 4, pp. 399-411, 2011.

[20] H. C. Glass, A. T. Costarino, S. A. Stayer, C. M. Brett, F. Cladis, and P. J. Davis, "Outcomes for extremely premature infants," Anesthesia \& Analgesia, vol. 120, no. 6, pp. 1337-1351, 2015.

[21] M. C. Allen, "Neurodevelopmental outcomes of preterm infants," Current Opinion in Neurology, vol. 21, no. 2, pp. 123-128, 2008.

[22] L. A. Foulder-Hughes and R. W. I. Cooke, "Motor, cognitive, and behavioural disorders in children born very preterm," Developmental Medicine \& Child Neurology, vol. 45, no. 2, pp. 97-103, 2003.

[23] L. Holsti, R. V. E. Grunau, and M. F. Whitfield, "Developmental coordination disorder in extremely low birth weight children at nine years," Journal of Developmental \& Behavioral Pediatrics, vol. 23, no. 1, pp. 9-15, 2002.

[24] N. M. Davis, G. W. Ford, P. J. Anderson, and L. W. Doyle, "Developmental coordination disorder at 8 years of age in a regional cohort of extremely-low-birthweight or very preterm infants," Developmental Medicine \& Child Neurology, vol. 49, no. 5, pp. 325-330, 2007.

[25] A. Hall, A. McLeod, C. Counsell, L. Thomson, and L. Mutch, "School attainment, cognitive ability and motor function in a total scottish verylow-birthweight population at eight years: a controlled study," Developmental Medicine \& Child Neurology, vol. 37, no. 12, pp. 1037-1050, 1995.

[26] S. Saigal, P. Rosenbaum, P. Szatmari, and D. Campbell, "Learning disabilities and school problems in a regional cohort of extremely low birth weight $(<1000 \mathrm{~g})$ children: A comparison with term controls," Journal of Developmental \& Behavioral Pediatrics, vol. 12, no. 5, pp. 294-300, 1991.

[27] N. Marlow, L. Roberts, and R. Cooke, "Outcome at 8 years for children with birth weights of $1250 \mathrm{~g}$ or less," Archives of Disease in Childhood, vol. 68, no. 3, pp. 286-290, 1993.

[28] A. Powls, N. Botting, R. W. I. Cooke, and N. Marlow, "Motor impairment in children 12 to 13 years old with a birthweight of less than 1250 g," Archives of Disease in Childhood, vol. 73, no. 2, pp. F62-F66, 1995.

[29] J. F. de Kieviet, L. Zoetebier, R. M. van Elburg, R. J. Vermeulen, and J. Oosterlaan, "Brain development of very preterm and very low-birthweight children in childhood and adolescence: a meta-analysis.," Developmental Medicine \& Child Neurology, vol. 54, no. 4, pp. 313-323, 2012. 


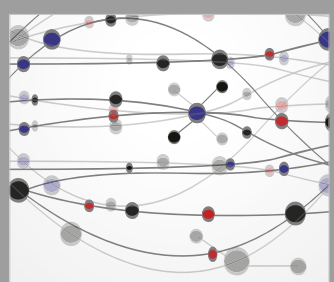

The Scientific World Journal
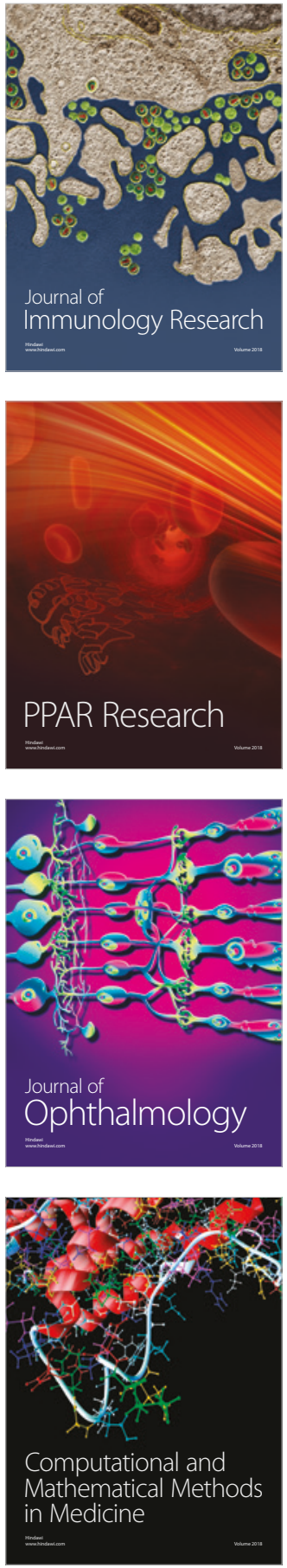

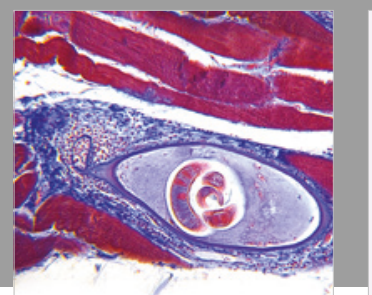

Gastroenterology Research and Practice

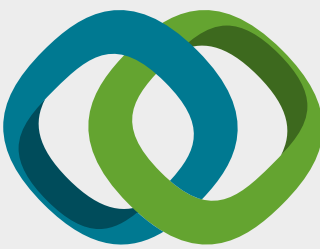

\section{Hindawi}

Submit your manuscripts at

www.hindawi.com
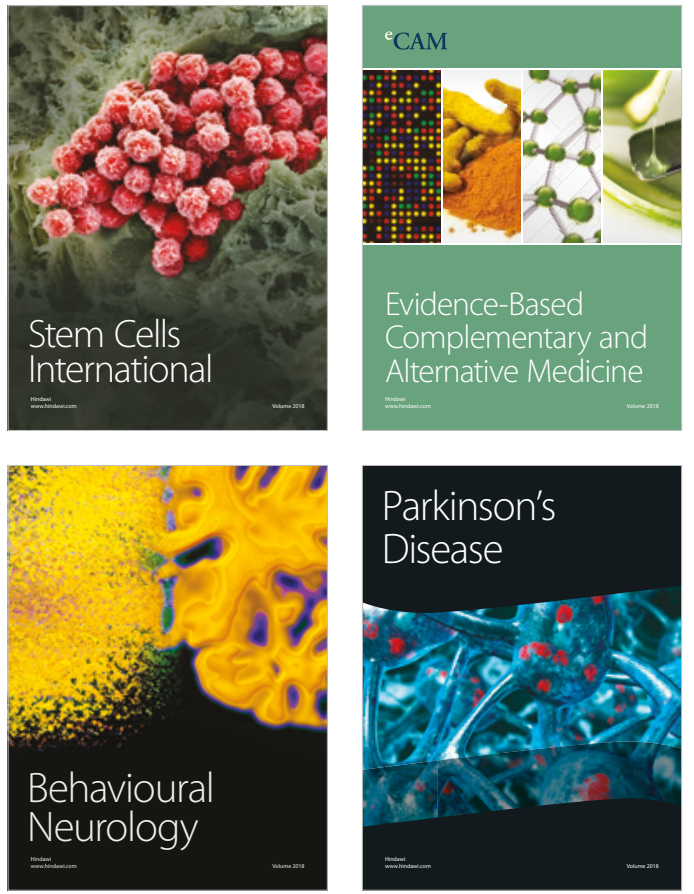

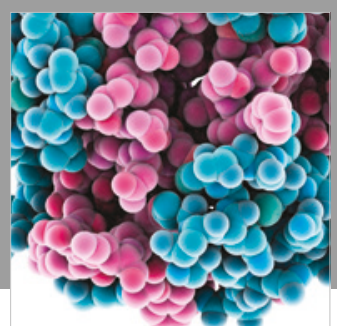

ournal of

Diabetes Research

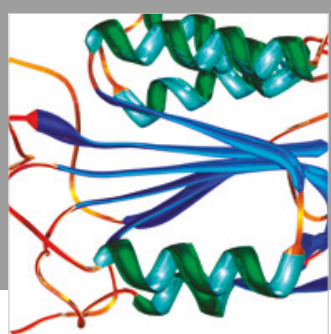

Disease Markers
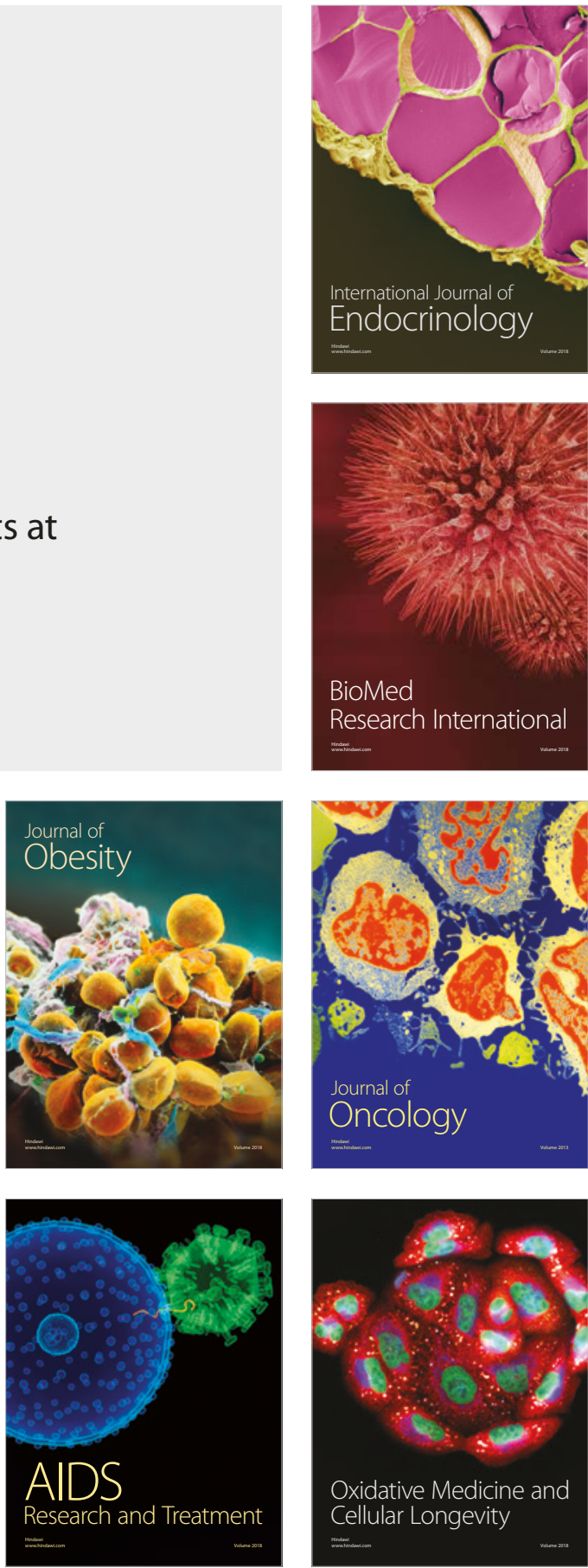